\title{
Knowledge, Competence of Indonesian Climbing Sports Athletes in the Prevention and Management of Injuries
}

\author{
Yustinus Sukarmin ${ }^{1}$, Ilham ${ }^{1, *}$, Hakim Irwandi Marpaung ${ }^{2}$, Ruri Famelia ${ }^{3}$, Anton Komaini ${ }^{4}$, \\ Galih Dwi Pradipta ${ }^{5}$ \\ ${ }^{1}$ Faculty of Sport Science, Yogyakarta State University, Yogyakarta, Indonesia \\ ${ }^{2}$ Department of Sport Science, Sekolah Tinggi Olahraga dan Kesehatan Bina Guna, Medan, Indonesia \\ ${ }^{3}$ Department of Human Science, The Ohio State University, Columbus, USA \\ ${ }^{4}$ Faculty of Sport Science, Universitas Negeri Padang, Padang, Indonesia \\ ${ }^{5}$ Faculty of Education, Universitas PGRI Semarang, Semarang, Indonesia
}

Received July 9, 2021; Revised September 6, 2021; Accepted October 17, 2021

\section{Cite This Paper in the following Citation Styles}

(a): [1] Yustinus Sukarmin, Ilham, Hakim Irwandi Marpaung, Ruri Famelia, Anton Komaini, Galih Dwi Pradipta , "Knowledge, Competence of Indonesian Climbing Sports Athletes in the Prevention and Management of Injuries," International Journal of Human Movement and Sports Sciences, Vol. 9, No. 6, pp. 1262 - 1271, 2021. DOI: 10.13189/saj.2021.090621.

(b): Yustinus Sukarmin, Ilham, Hakim Irwandi Marpaung, Ruri Famelia, Anton Komaini, Galih Dwi Pradipta (2021). Knowledge, Competence of Indonesian Climbing Sports Athletes in the Prevention and Management of Injuries. International Journal of Human Movement and Sports Sciences, 9(6), 1262 - 1271. DOI: 10.13189/saj.2021.090621.

Copyright $\bigcirc 2021$ by authors, all rights reserved. Authors agree that this article remains permanently open access under the terms of the Creative Commons Attribution License 4.0 International License

\begin{abstract}
Despite the growing pace of climbing sports in Indonesia, the level of injury prevention and management could be among extraneous factors that may impede the athlete's achievement in such game. As a lack of adherence to preventive strategies is problematic in injury avoidance, the main purpose of the study is to determine/find out whether there is a significant relationship between variances-variables and variable-indicators along with disclose the level of knowledge, resources, and the ability in injury prevention and management among athletes. The nature of the research is descriptive with the mixed method where its approach was tested using structural equation modeling involving 76 athletes from all Indonesian provinces. Data were analyzed using Statistical Package for Social Sciences (SPSS, Version 23) and Partial Least Square Structure Equation Modelling. Results showed that information about their level of knowledge and competence towards prevention and management of injuries was still needed for improvement based on the values of data harvested and analyzed. There should be a significant correlation among research variable and indicators. However, not all data justified such relationship, where for some P-calculated was greater than 0.05 as the conventional scale. It is recommended that a certain
\end{abstract}

program be designed and implemented that may nurture the improvement of athletes' skills and knowledge by giving them service training for the same purpose.

Keywords Knowledge, Competence, Climbing, Injury Prevention, Injury Management

\section{Introduction}

In recent decades and hereupon, extreme physical sport-related pursuits such as climbing not only have emerged as recreational activities but also have evolved into competition mainstream sporting disciplines [1] [2]. Leisure activity, competition environments, and practices have also been developing globally as the growing sport climbing practice since the onset of the world championships held in Germany in 1991. To date, the sport of climbing is among the disciplines included in the 2020 Olympic games official program in Tokyo. Despite the growing pace of this sport, the systematic and intensified training of athletes in such games, however, without basics and correct knowledge and competence for prevention and management of sports injuries techniques, 
existing sports injuries will likely weaken or plague the qualitative benefits bonded to sports activity. In a broad sense, knowledge especially in human life plays an important role and it is one of the features that helps to make differences between humans and animals. Having normal intuition determines the success in the life event in general and injury management in particular. According to [3], like other events such particular knowledge also play an important role in sports to prevent injuries and other sports related physical hazards. Thus, knowledge about prevention and management of injuries become important things that should be known by athletes or climber lovers for the sake of reducing psychological tensions and fear and danger that can be set, thereby climbers can focus on the physical, technique, and tactics during a climbing [4]. Additionally, a sound knowledge of sports injuries prevention and management is a staple and very essential for sports athletes, both for a coach and an individual who is attached to the field of sports directly or indirectly. In contrast, injury can impede or destroy the future of an athletes and it can be prevented.

In a broad sense, static stretching, warm-up before and cool down after exercise, strength, and conditioning, landing technique, and correct application of protective tools are all about the main components of sports injury prevention [5] [6]. Hence, previous studies have reported disparity in knowledge and needs for prevention and management of sports injury among climbing athletes and fans. For example, [7] investigates an incidence of sports injuries among 8,700 Massachusetts individuals, which indicated that $3.4 \%$ of them mostly schoolchildren still required hospital interventions after a sports injury. In the same vein, [8] [9] had also demonstrated in a study with 11.840 students, who aged 14-17 are at the high-risk group for a sports injury. A study conducted on knowledge of prevention and management of sports injury among junior college students in age between 15 and 20 years old in Taiwan, exhibited that despite being conscious about the importance of preventing sports injury, a substantial portion of them did not possess correct intuition for sports injury management [10]. In connection with that, the level of knowledge among 200 graduating students of the Department of Physical Education from three different universities in Taiwan on prevention and management of sports injury showed that their average scores fell in the low category/level (Mohammed, et al., 2014). From these facts above, one may wonder how better sports climbing athletes in Indonesia they are so far especially in the injury preventions and how injury occurs to them.

Safety both in sports and physical activity are important prerequisites that must be considered [12], as well as maintained in the wake of an active and healthy lifestyle [13]. Then, the occurrence of the injury and its severity in the sport of rock climbing is caused by the competence of disciplines, equipment needed, the nature of the race track, which is a sport of rock-climbing encompassing rock climbing, wall climbing, indoor climbing, etc. [14]. Competence can be described as the combination of training, skills, experience and knowledge that a person has and their ability to apply them to perform a task safely [15]. However, our concern in this study is to what extent such competence is applied to in injuries avoidance during climbing sports for athletes. The performance of climbers, difficult paths, the tools used, the surface of the rock, location, altitude, and the climate are the main parameters that have strong implications and effects on the risk occurrence during climbing execution. Prevalence injuries mostly reported especially during rock climbing are: nail injuries, collateral ligaments, finger injuries, pain, non-specific pain finger, an injury in other ligaments in the finger, and so forth [16]. Flexor pulley lesions, fractures, strains, and ligament lacerations, wounds, dislocations, other disorders are also types of injuries frequently experienced by some of these individuals.

Various researchers have put their efforts to estimate the proportion of different types of injury that often trigger and subsequentially hamper athlete's performance. Research concerning the evaluation of injury to 560 climbers with injuries most often injury was found on feet $(29.2 \%)$, radius $(28.6 \%)$, and leg $(16.2 \%)$. But ligament injuries were represented by $(36.8 \%)$; contusions $(15.2 \%)$, fractures $(15.0 \%)$, and tendon injuries $(10.6 \%)$ as the most common injury contested [17].

Although nowadays sports foster both the physical and mental health of young generations in general and sport climbing athletes in particular, in the absence of proper knowledge, skills of sports injury prevention and management, the loss would be greater than the gain when one accidentally gets injured or hurt. From the after-effects of sports injuries, we know so far that, students (since it is mostly liked by students) and other climbing sports athletes should improve their knowledge of sports injury prevention and management in order to avoid both physical and mental injuries [18], [19]. Without these bits of knowledge and skills in rock climbing, the better achievement will be difficult to reach, since they are among staple and necessary preparations for the safety of athletes during training or competition moments. It is also suggested that providing them some hints containing knowledge related to sports injuries, understanding the meaning of injury, type of injury, as well as the proper handling, would serve them as additional assets [20]. It may save lives, prevent the occurrence of defects, prevent infection, prevent a decline in the general conditions, and speed healing. Additionally, the level of injury can basically be reduced if the athlete is instructed to determine the prevention and treatment of injury rock climbing.

Given the current limited and disparity in knowledge, skills (competence) from Indonesian climbing sports athletes in the prevention and injuries management that 
may plague climbing performance, our first interest emerged is to determine the level of knowledge and competence of athletes on injury prevention and control during and after rock climbing. To portray the current situation and improve recognition of knowledge, competence, prevention, and injuries management as the needs of sports climbing athletes will be the main contribution of our present product.

\section{Research Methods}

Subjects were selected from all provinces of Indonesia using the representative random sampling (RRS) technique. This research approach is a basic type of sampling, where a sample is considered representative when either sample characteristics or inferences from the sample approximate population values [21] [22]. 76 athletes were selected from all provinces, representing the sample size in this study and they were distributed as follows: 18 from West-Sumatra; 2 from Riau Island, 5 from central Jawa, 4 represent central Sulawesi, 1 from Bengkulu, 2 from East-Kalimantan, 6 from Riau, and so forth. The structure of the questionnaire was adopted from [23] and developed in accordance with the gist of the study. This instrument developed for the sake of the study consists of 3 main parts: the background of personal information; a source of knowledge, and then a knowledge test; Background personal information include: gender, rock climbing organization, club, climbing ability [24], Experience injury last year, the number of workouts per week, duration of exercise per day and its relation to sports injuries rock climbing were factors to assess. As far as the source of information is concerned, it was in the form of how the athletes during climbing participation acquire knowledge about prevention and management of injuries in climbing sports. However, for knowledge tests, with the approval of Wang and Huang "the questionnaire in the knowledge of Sports Injury Prevention and management" was adopted in this study.

\section{a Verification of Instrument Validity and Reliability}

Before being administrated to the subject, content validity was tested by 10 experts. 4 of them were from medical professions in the field of treatment and prevention of sports, three others were doctors of exercise and rehabilitation of sports injuries, and the rest three validators were instructors/trainers with a national certificate in rock climbing over 10 years of experience. Moreover, Data was validated by statistical analysis PLS-SEM and reliability of the instrument was tested based on the values of Cronbach's, Alpha scale. In tandem, statistical analysis of data was done with SPSS application (SPSS, version 23) along with PLS-SEM. While analyzing data, mathematical statistics such as the data arithmetic mean ( $\mathrm{x}$ ) and standard deviation (s) were recalled.

\section{b Structural Equation Modeling}

Diagram 1 below will help us to understand the correlational aspects that exist between research indicators and variables. As viewed in our equation modeling, the structural equation Modelling of this research has five variables and fourteen indicators attributed as follows: five variables (prevention, management, source knowledge, and competence and knowledge. three indicators (level, qualification, and sponsorship) for injury prevention, three indicators (media parenting, training, volume training) for injury management variables, two indicators (school learning, and experience) for variable source knowledge, and the rest six others for variable competence and knowledge that is competence, injury coaches, injury level. Practice for competence, and injury management, injury prevention for knowledge. In other words, the relationship of these variables and indicators can be presented as below:

a. Prevention (X1): independent variable

b. Management (X2): independent variable

c. Source of knowledge (Y1): dependent variable

d. Competence injuries management (Y2): dependent variable

Notwithstanding, this study is guided by the research hypothesis set up as follows:

H1: There is a correlation between indicators and variables.

H2: There is a correlation between the dependent variable and the independent variable. 


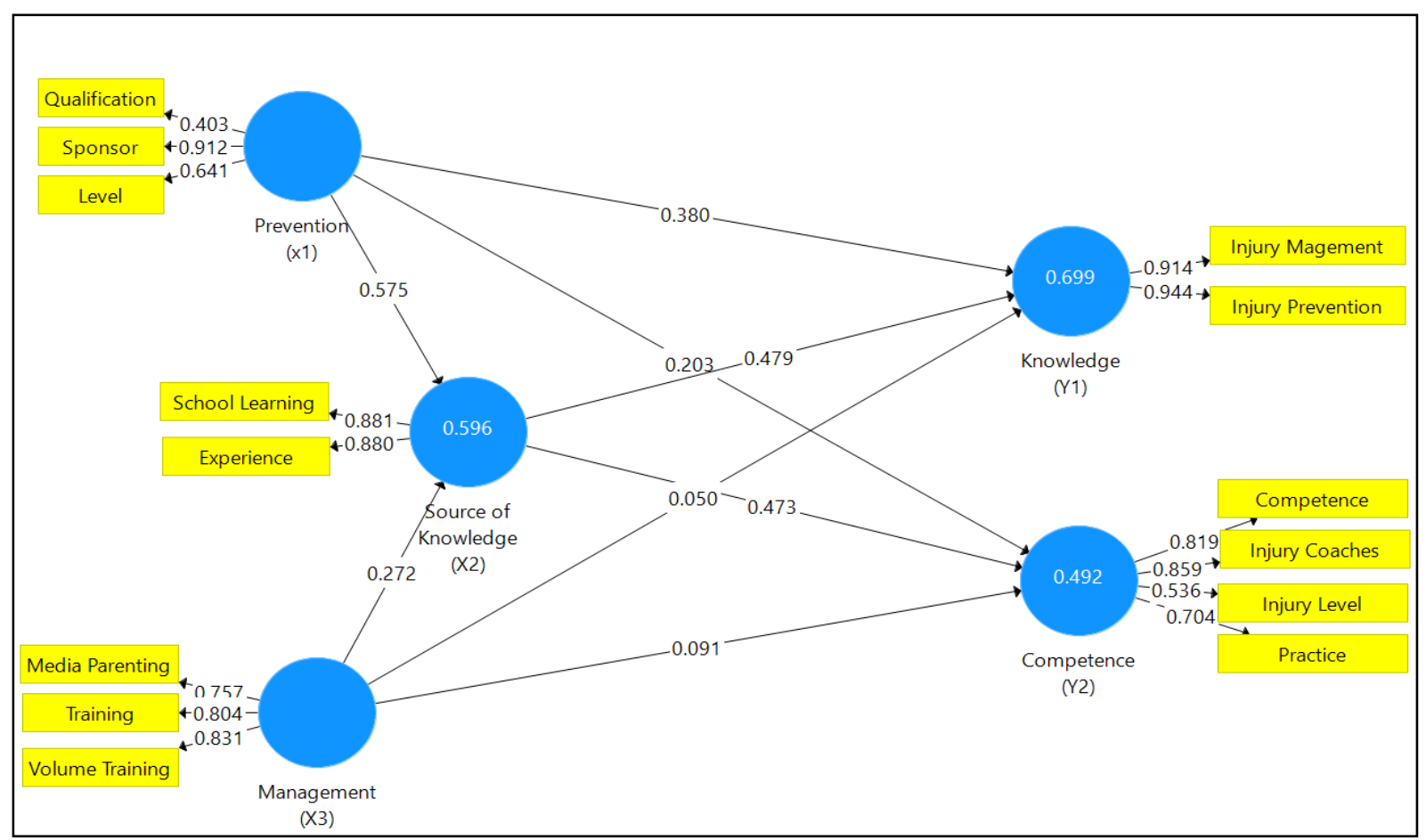

Diagram 1. The relationship between research variable and indicators

Table 1. Biodata and Respondent Distribution Profile

\begin{tabular}{|c|c|c|c|c|c|c|c|c|}
\hline \multicolumn{6}{|c|}{ Gender and age distribution } & \multicolumn{3}{c|}{ Gender and age frequency } \\
\hline \multicolumn{2}{|c|}{} & Gender & Age & Age freq. & & Gende freq. \\
\hline \multirow{2}{*}{ age N } & Valid & 76 & 76 & $10-15(5$ respondents $)$ & Male & female & Frequ. & $\%$ \\
\cline { 2 - 9 } & Missing & 0 & 0 & $16-20(26$ respondents $)$ & 49 & & 49 & 64.5 \\
\hline Mean & 1.36 & 23.11 & $21-25(26$ respondents $)$ & & 27 & 27 & 35.5 \\
\hline Median & 1.00 & 21.00 & $26-30(9$ respondents $)$ & & & & \\
\hline Std. Deviation & .482 & 7.778 & $31-35(6$ respondents $)$ & & & & \\
\hline Variance & .232 & 60.495 & $36-40(2$ respondents $)$ & & & & \\
\hline Range & 1 & 47 & $>40(2$ respondents $)$ & & & & \\
\hline Minimum & 1 & 13 & & & & & \\
\hline Maximum & 2 & 60 & & & & & \\
\hline Sum & 103 & 1756 & & & & & \\
\hline
\end{tabular}

\section{c Data Analysis Process}

By employing the PLS-SEM method and the statistical software Smart-PLS to estimate the model in this study, namely the nature of relationships that may exist in research variables and indicators [25]. The software PLS-SEM is a multivariate analysis approach used to estimated path models with latent variables whereas software SPSS is broadly understood as a commercially distributed software suite for data management and statistical analysis [26].

\section{Analysis and Results}

This table showcases the biodata and respondents' distribution profile partook in in this study. As mentioned in the preceding paragraph, 76 individuals were pointed out to be the sources of necessary information. Among these individuals, the prevalence of their number were males represented at $64.5 \%$ from 49 respondents to 76 as the total. Only $35.5 \%$ otherwise 27 subjects represent the rest of the sample size we used. As far as the aged distribution is concerned, through this table 1, the age frequency was attributed and distributed as follows: five individuals with an age range of 1 and 15, 26 respondents with ages range of 16-20, and 21-25 respectively. However, only 9 respondents' ages range between 31-35, and so forth (see table 1 for more detail information). 
Table 2. Output for construct validity and reliability

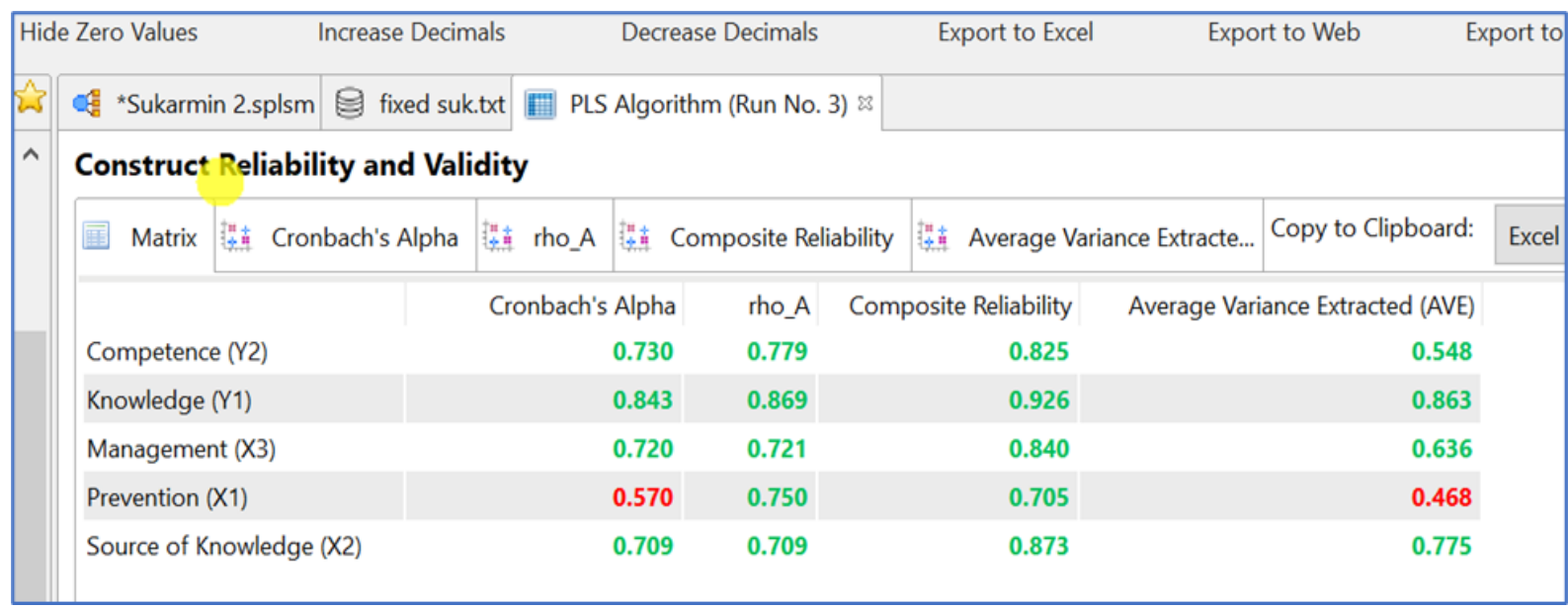

By accessing data with two software, that is SPSS and PLS-SEM, this involving assessing the relationships between the latent variables and their associated items through research indicators. The most central concern to verify/testing is the status of data reliability and validity. For [27], validity explains the extent to which a test measures what is presumed to measure/accuracy. Internal consistency reliability and convergence validity are often assessed by way of two key coefficients; composite reliability (CR) and average variance extracted (AVE). Thus, in this study, the measurement models used has five main constructs along with fourteen indicators. Asserted by [25], in assessing reliability of a model, the loading of each indicator on its associated latent variables must be verified and compared to the conventional threshold existing so far. For [28], the output loadings should be higher than 0.7 for indicators reliability/composite reliability to be considered acceptable [29]. In our study, all composite reliability values were cohesive with such assumption and loaded above the 0.70 as the recommended value. The lowest and highest values were 0.705 and 0.926 respectively. According to [30], if the AVE value is greater than 0.5 , the indicator/items measuring the variable can be said to be valid and reliable. On the side of Cronbach's alpha values, loading values were also above 0.7 except on one variable called injury prevention loads at 0.570 . The rho_A is also used for assessing construct reliability, which should be higher than 0.7 to establish internal consistency. Based on the results we have, it is seen that all research variables loading values were higher than 0.70 distributed from 0.709 as the lowest and 0.869 as the highest value. Thus, with these data harvested, we may conclude that the measurement model and calculations of our study possessed acceptable reliability. See more information in table 1.
Table 3. The Outputs of Collinearity Assessment (VIF)

\begin{tabular}{|c|c|c|c|}
\hline *Sukarmin 2.splsm & \multicolumn{2}{|c|}{$\theta$ fixed suk.txt } & PLS Algorithm \\
\hline \multicolumn{4}{|c|}{ Collinearity Statistics (VIF) } \\
\hline \multirow[t]{2}{*}{ Outer VIF Values } & I & Inner VIF Values & \\
\hline & & VIF & \\
\hline Competence & & 1.626 & \\
\hline Experience & & 1.432 & \\
\hline Injury Coaches & & 1.855 & \\
\hline Injury Level & & 1.267 & \\
\hline Injury Magement & & 2.130 & \\
\hline Injury Prevention & & 2.130 & \\
\hline Media Parenting & & 1.148 & \\
\hline Practice & & 1.339 & \\
\hline Qualification & & 1.335 & \\
\hline School Learning & & 1.432 & \\
\hline Sponsor & & 1.088 & \\
\hline Training & & 2.128 & \\
\hline Volume Training & & 2.190 & \\
\hline Level & & 1.426 & \\
\hline
\end{tabular}

Apart from assessing or testing the state of construct reliability and validity, collinearity was also tested and verified. Thus, the variance inflation factor henceforth VIF is all about. Our data showed that the value or output of collinearity statistics (VIF) loading ranging from 1.148 to 2.190 . As a rule of thumb, we need to get data that have a variance inflation factor of 5 or lower to avoid the collinearity problem [31] [28]. With this later statement, the conclusion of VIF in our study is well in the range of the threshold value (1.148 to 2.190$)$ which said that collinearity is not a problem in our study. 
Table 4. Discriminant Validity among Variables

\begin{tabular}{|c|c|c|c|c|c|c|}
\hline \multicolumn{7}{|c|}{ Discriminant Validity } \\
\hline \multicolumn{2}{|c|}{ Fornell-Larcker Criteri.. } & \multicolumn{2}{|c|}{ Cross Loadings } & \multicolumn{2}{|c|}{ 圆 Heterotrait-Monotrait ... } & \multirow{2}{*}{. Fis Heterotrait } \\
\hline Compete... & $\begin{array}{c}\text { Compete.... K } \\
0.740\end{array}$ & Knowled... & Manage... & Preventio... & Source of... & \\
\hline Knowled... & 0.731 & 0.929 & & & & \\
\hline Manage... & 0.510 & 0.581 & 0.798 & & & \\
\hline Preventio... & 0.609 & 0.766 & 0.612 & 0.684 & & \\
\hline Source of... & 0.680 & 0.792 & 0.624 & 0.741 & 0.880 & \\
\hline
\end{tabular}

The next calculation concerns the extent to which the value of discriminant validity is among variables. "Mastering Partial Least Squares Structural Equation Modeling (PLS-SEM) with Smart-PLS in 38hour is one book's title of existing books written by Prof Dipak C. Jain 2019 that explaining two paths to rely on while checking discriminant validity, namely the Fornell-Larcker Criterion and HTMT. The classical approach is proposed by Fornell and Larcker (1981) who suggested that the square root of AVE in each latent variable can be used to set up discriminant validity if this value is larger than other correlation values among the latent variables. By that, a table is created in which the square root of AVE is manually calculated and written on the diagonal of the table. For example, variables involving in this calculation were competence, knowledge, management, prevention, and source of information. Then, for athlete competence, the AVE is found to be 0.548 , hence its square roots on the same variable (competence) becomes 0.740 . This number is larger than the correlation values in the column of competence $(0.731,0.510,0.609$, 0.680 , respectively). A similar observation is also made for the latent variable of knowledge level, management, prevention, source of knowledge (Tables $1 \& 3$ ). The present results indicate that discriminant validity is well established among research variables.

To simply understand the gist of the results above based on our research purpose, we look at the $P$-value column to see the linear effect. It can be seen that in the management (X3) and competence (Y2) row, the resulting P-value is 0.544 , which means that it is larger than our significant level of 0.05 . As a result, we accept that the hypothesis that testing such relation does not hold any significant non-linear. Likewise, between management and knowledge and prevention and competence, all results having P-value larger than 0.05. However, for management together with a source of knowledge, prevention, and knowledge, prevention and source of knowledge, source of knowledge and competence, source of knowledge and knowledge, all these data loads under P-value $<0.05$. Overall, there is both a weak and strong relationship between the combination indicators-variables and between variables themselves. Thus, it can be concluded that, the only hypothesis with data with P-calculated lower than 0.05 exhibits linear effects.

Table 5. Outputs from Hypothesis testing P-value

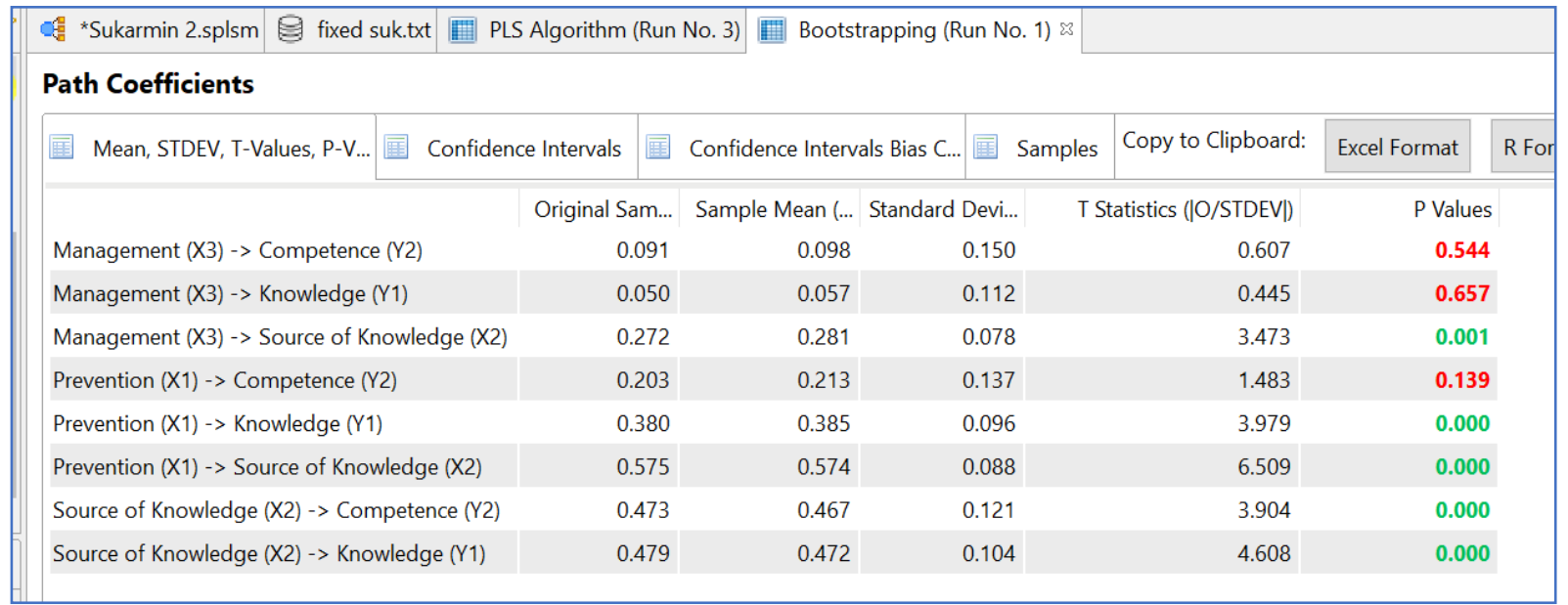


Table 6. Outputs correlational results among research constructs

\begin{tabular}{|c|c|c|c|c|c|c|c|c|}
\hline \multicolumn{9}{|c|}{ Correlations } \\
\hline & & Gender & Knowledge & $\begin{array}{c}\text { Injury } \\
\text { management }\end{array}$ & $\begin{array}{c}\text { Source } \\
\text { Knowledge }\end{array}$ & $\begin{array}{c}\text { Injury } \\
\text { Prevention }\end{array}$ & Competence & Age \\
\hline \multirow{3}{*}{ Gender } & Pearson Correlation & 1 & .076 & .134 & .057 & .214 & .012 & -.113 \\
\hline & Sig. (2-tailed) & & .514 & .249 & .623 & .063 & .919 & .330 \\
\hline & $\mathbf{N}$ & 76 & 76 & 76 & 76 & 76 & 76 & 76 \\
\hline \multirow{3}{*}{ Knowledge } & Pearson Correlation & .076 & 1 & $.509^{* *}$ & $.549^{* *}$ & $.717^{* *}$ & $.547^{* *}$ & .096 \\
\hline & Sig. (2-tailed) & .514 & & .000 & .000 & .000 & .000 & .411 \\
\hline & $\mathbf{N}$ & 76 & 76 & 76 & 76 & 76 & 76 & 76 \\
\hline \multirow{3}{*}{$\begin{array}{c}\text { Injury } \\
\text { management }\end{array}$} & Pearson Correlation & .134 & $.509^{* *}$ & 1 & $.627^{* *}$ & $.728^{* *}$ & $.544^{* *}$ & .166 \\
\hline & Sig. (2-tailed) & .249 & .000 & & .000 & .000 & .000 & .152 \\
\hline & $\mathbf{N}$ & 76 & 76 & 76 & 76 & 76 & 76 & 76 \\
\hline \multirow{3}{*}{ Source Knowledge } & Pearson Correlation & .057 & $.549^{* *}$ & $.627^{* *}$ & 1 & $.710^{* *}$ & $.559^{* *}$ & .098 \\
\hline & Sig. (2-tailed) & .623 & .000 & .000 & & .000 & .000 & .398 \\
\hline & $\mathbf{N}$ & 76 & 76 & 76 & 76 & 76 & 76 & 76 \\
\hline \multirow{3}{*}{ Injury Prevention } & Pearson Correlation & .214 & $.717^{* *}$ & $.728^{* *}$ & $.710^{* *}$ & 1 & $.638^{* *}$ & .063 \\
\hline & Sig. (2-tailed) & .063 & .000 & .000 & .000 & & .000 & .589 \\
\hline & $\mathbf{N}$ & 76 & 76 & 76 & 76 & 76 & 76 & 76 \\
\hline \multirow{3}{*}{ Competence } & Pearson Correlation & .012 & $.547^{* *}$ & $.544^{* *}$ & $.559^{* *}$ & $.638^{* *}$ & 1 & .197 \\
\hline & Sig. (2-tailed) & .919 & .000 & .000 & .000 & .000 & & .087 \\
\hline & $\mathbf{N}$ & 76 & 76 & 76 & 76 & 76 & 76 & 76 \\
\hline \multirow{3}{*}{ Age } & Pearson Correlation & -.113 & .096 & .166 & .098 & .063 & .197 & 1 \\
\hline & Sig. (2-tailed) & .330 & .411 & .152 & .398 & .589 & .087 & \\
\hline & $\mathbf{N}$ & 76 & 76 & 76 & 76 & 76 & 76 & 76 \\
\hline
\end{tabular}

With the p-value standard 0.05 , and the correlation significant at the 0.01 level (2-tailed), we view from this table above shows that knowledge, competence, age and genders are somehow and, in some cases, correlated with injury management and prevention. Based on the Pearson correlation values, when correlating gender with knowledge, the p-value was not significant since it was equal to 0.514 , likewise for gender with injury management, source of knowledge injury prevention competence and age. However, knowledge was found correlated with injury management and other construct with p-calculated 0.000 , except age where p-calculated was superior at 0.05 (0.411). Age factor was not correlated in any constructs employed with all its values superiors at 0.05 as maximum threshold.

\section{Discussion}

This is the first study of knowledge, prevention, and management injuries among sports climbing athletes that are reporting prevalence disparities of knowledge and competence on the prevention and injuries management within respondents fascinate in such sports. Furthermore, with 76 individuals as the source of information in this study, it has been shown that knowledge has strong effects on injuries prevention and management. By analyzing the link between knowledge, skills, source of knowledge on injury management and prevention, we have realized that the substantial portion our results has exhibited such relationship specifically between independent and dependent variables. Since this study on hands is conducted on athletes with various and multiple variables (five main variables and fourteen indicators), we argue that it will contribute to the literature review in terms of being different from the researchers conducted or seek the effects of one single or two variables together.

The results of the sample employed, structural equation modeling (SEM), linear effect, and statistic calculations prove that there was a significant relationship between latent variables and their respective indicators. For example, source of knowledge and management shows a correlation value larger than 0.596 , which means construct reliability and validity are acceptable. The latter evidence was corroborated with the one reported by [32] who investigated the prime prevention strategies in slowing the aging process amongs Njala University, Njala Campus Athletes in Njala, Southern Sierra Leone. As a result, a 
significant relation was found between athletes' knowledge and injury prevention in sports. When seeking the relationship between the source of knowledge and injury management, the loading value was 0.492 , which means weak liaison, without forgetting the strong relationship found between knowledge and management equal to 0.699 .

While testing our research hypothesis with P-calculated lower than 0.05 , we have seen that linear effects were found in some cases. For example, management and source of knowledge verified this relation with P-calculated equal to 0.001 , prevention and knowledge 0.000 , prevention and source of knowledge, source of knowledge and competence, source of knowledge and knowledge, all have P-calculated lower than .05 (see table 5). However, our hypothesis testing P-value was not significant when testing linear effect between injury management and competence, P-calculated $=0.544$, injury management with knowledge, P-calculated greater than 0.05 , that is .657 , and for injury prevention and competence 0.139 . Through correlational scrutinization along with the depiction values found in the table 6 , no significant difference in the age and gender distribution on knowledge for prevention and management of sports Injury was observed with significant values. However, strong correlation was found between knowledge, competence on injury prevention and injury management. Details information were not analysed to reveal such discrepancy based on ages distributions. With respect of our findings, the study of [33] on first-aid knowledge among vocational school students in Kinmen region, pointed out that no significant difference was observed between sports injury experience and first-aid knowledge which is consistent with the finding in this study on the aspect of knowledge, competence have significant correlation with the rest on the study variable except on gender and age distribution.

To sum up, our message is to appeal to all climbing sports athletes to be more vigilant by knowing how to prevent and deal with or handling injures when they occur. Corroborated with existing literature so far, without the knowledge of prevention and treatment in such sports pursuit, goals or achievement will be difficult to accomplish because it is a basic preparation that is necessary for the sake and safety of athletes. As a suggestion, it is better to provide the knowledge related to sports injuries, understand the meaning of injury, type of injury, as well as the proper handling for the climber lovers. It is worthy mentioning some researchers and injury proportions that frequently occur to rock climbing athletes. Ligament injuries were reported by [34] to often occur on the fingers and toes while tendon injuries often occur on the fingers and arms [35], bruising injury often occurs in the legs and back [36]. As injury proportion is concerned, [37], reveal more about the sport of rock climbing injury, found the result that $65.3 \%$ of patients with nail disease, followed by recurrent ankle sprains
(27.8\%), retrocalcaneal bursitis (19.4\%), Achilles tendinitis (12.5\%), metatarsalgia (12.5\%), and plantar fasciitis $(5.6 \%)$ [32]. In addition, for these latter authors, the injury occurs because of the type of shoe sizes that need the use of a small size.

\section{Conclusion}

The content of our research findings has revealed the extent to which the relationships between variables themselves or between variables and indicators are. Based on the discussions that have been put forward, the conclusion can be drawn. Achievement is the high quality of any physical activity and is all athletes' dreams about; however, in rock climbing, it seems difficult to accomplish without having staple prerequisites to prevent and manage the injury that may occur during performance. Since correlation traits have been found within most research variables and indicators, means improvement is needed especially by strengthening intuition within rock climbing athletes. Therefore, precautions for empowering these liaisons found in this present study should be improved by taking into consideration the quality of knowledge, skills, and source of knowledge which subsequently help in injuries prevention and management. At the same time, it is important to design and implement a certain program that may nurture to improve athletes' skills and knowledge by giving them service training for the same purpose (improve athlete performance and avoid injuries).

\section{Acknowledgment}

The authors would like to express their appreciation to all who participate in this study and make it possible as it so far. They acknowledged that without their enthusiasm and willingness, nothing would have been possible or done.

\section{Limitation}

Acknowledge the disparity in knowledge and competence for prevention and management of sports Injury for Indonesian climbing sports Athletes as well as the needs for such knowledge among male and female students. Our study was limited to present and analyse clearly how age and gender distribution might contribute in injury prevention and management among subjects used in this current study. A sample size of 76 respondents was not enough to infer that the status on climbing athletes in terms of knowledge distribution and competence is reliable and consistent as portrayed in this study. 


\section{REFERENCES}

[1] F. A. Rahman and A. Kristiyanto, "Mountaineering physical activities as community recreational sports," $J$. Pendidik. Teor. Penelitian, Pengemb., vol. 3, no. 3, pp. 398-405, 2018

[2] X. Sanchez, M. Torregrossa, T. Woodman, G. Jones, and D. J. Llewellyn, "Identification of parameters that predict sport climbing performance," Front. Psychol., vol. 10, no. MAY, pp. 1-10, 2019, doi: 10.3389/fpsyg.2019.01294.

[3] J. P. Sharma, "Assessment of the status of injury knowledge prevention and management at various levels of sports persons," vol. 2, no. 2, pp. 505-507, 2017.

[4] G. Grønhaug and M. Norberg, "First overview on chronic injuries in sport climbing: proposal for a change in reporting of injuries in climbing," BMJ Open Sport Exerc. Med., vol. 2, no. 1, p. e000083, 2016, doi: 10.1136/bmjsem-2015-000083.

[5] A. J. Shield and M. N. Bourne, "Hamstring Injury Prevention Practices in Elite Sport: Evidence for Eccentric Strength vs. Lumbo-Pelvic Training," Sport. Med., vol. 48, no. 3, pp. 513-524, 2018, doi: 10.1007/s40279-017-0819-7.

[6] T. J. A. Lopes, M. Simic, G. D. Myer, K. R. Ford, T. E. Hewett, and E. Pappas, "The Effects of Injury Prevention Programs on the Biomechanics of Landing Tasks: A Systematic Review With Meta-analysis," Am. J. Sports Med., vol. 46, no. 6, pp. 1492-1499, 2018, doi: $10.1177 / 0363546517716930$.

[7] S. S. Gallagher, K. Finison, B. Guyer, and S. Goodenough, "The incidence of injuries among 87,000 Massachusetts children and adolescents: Results of the 1980-81 statewide childhood injury prevention program surveillance system," Am. J. Public Health, vol. 74, no. 12, pp. 1340-1347, 1984, doi: 10.2105/AJPH.74.12.1340.

[8] T. Jap, S. Tiatri, E. S. Jaya, and M. S. Suteja, "The Development of Indonesian Online Game Addiction Questionnaire," PLoS One, vol. 8, no. 4, 2013, doi: 10.1371/journal.pone.0061098.

[9] U. States, "National Health Statistics Reports, Number 99, November 18, 2016," Centers Dis. Control Prev., no. 99, pp. 2011-2014, 2016.

[10] A. S. Y. Lee, M. Standage, M. S. Hagger, and D. K. C. Chan, "Sport injury prevention in-school and out-of school? A qualitative investigation of the trans-contextual model," PLoS One, vol. 14, no. 9, pp. 1-16, 2019, doi: 10.1371/journal.pone.0222015.

[11] G. Mohammed, S. Md Said, A. Azuhairi, Ariffin, and J. Kamaruzaman, "Physical Inactivity and Its Associated Factors among University Students," IOSR J. Dent. Med. Sci., vol. 13, no. 10, pp. 119-130, 2014, doi: 10.9790/0853-13101119130.

[12] Ilham and Dimyati, "The effect of visualization, relaxation, and self-efficacy on the performance of men speed world record athletes category," Int. J. Hum. Mov. Sport. Sci., vol. 9, no. 1, pp. 48-55, 2021, doi: 10.13189/saj.2021.090107.
[13] E. A. L. M. Verhagen, M. M. Van Stralen, and W. Van Mechelen, "Behaviour, the Key Factor for Sports Injury Prevention," Sport. Med., vol. 40, no. 11, pp. 899-906, 2010, doi: 10.2165/11536890-000000000-00000.

[14] V. Schöffl, A. Morrison, I. Schöffl, and T. Kpper, "The epidemiology of injury in mountaineering, rock and ice climbing," Med. Sport Sci., vol. 58, no. July, pp. 17-43, 2012, doi: 10.1159/000338575.

[15] T. Songer et al., "Core competencies for injury and violence prevention," Am. J. Public Health, vol. 99, no. 4, pp. 600 606, 2009, doi: 10.2105/AJPH.2008.137331.

[16] K. Y. Woollings, C. D. McKay, J. Kang, W. H. Meeuwisse, and C. A. Emery, "Incidence, mechanism and risk factors for injury in youth rock climbers," Br. J. Sports Med., vol. 49, no. 1, pp. 44-50, 2015, doi: 10.1136/bjsports-2014-094067.

[17] G. Grønhaug, "Self-reported chronic injuries in climbing: Who gets injured when?," BMJ Open Sport Exerc. Med., vol. 4, no. 1, pp. 3-5, 2018, doi: 10.1136/bmjsem-2018-000406.

[18] D. J. Caine, “Oajsm-7-099,” pp. 99-113, 2016.

[19] "Physical activity guidelines for Americans.," Okla. Nurse, vol. 53, no. 4, p. 25, 2008, doi 10.1249/fit.0000000000000472.

[20] S. W. Talpey and E. J. Siesmaa, "Sports Injury Prevention: The Role of the Strength and Conditioning Coach," Strength Cond. J., vol. 39, no. 3, pp. 14-19, 2017, doi: 10.1519/SSC.0000000000000301.

[21] A. Orozco, Undang-Undang Nomor 1 Tahun 2005 tentang Sistem Keolahragaan Nasional, A. Orozco, Undang-Undang Nomor 1 Tahun 2005 tentang Sistem Keolahragaan Nasional, and A. Orozco, No 主観的健康感 を中心とした在宅高齢者における健康関連指標に関

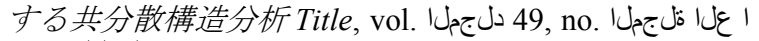
2008.

[22] X. Meng, "Scalable simple random sampling and stratified sampling," 30th Int. Conf. Mach. Learn. ICML 2013, vol. 28, no. PART 2, pp. 1568-1576, 2013.

[23] A. Wang, M. Guess, K. Connell, K. Powers, G. Lazarou, and M. Mikhail, "Fecal incontinence: A review of prevalence and obstetric risk factors," Int. Urogynecol. J., vol. 17, no. 3, pp. 253-260, 2006, doi: 10.1016/j.ijproman.2005.11.006.

[24] N. Draper et al., "Comparative grading scales, statistical analyses, climber descriptors and ability grouping: International Rock Climbing Research Association position statement," Sport. Technol., vol. 8, no. 3-4, pp. 88-94, 2015, doi: 10.1080/19346182.2015.1107081.

[25] S. M. Rasoolimanesh, C. M. Ringle, M. Jaafar, and T. Ramayah, "Urban vs. rural destinations: Residents' perceptions, community participation and support for tourism development," Tour. Manag., vol. 60, pp. 147-158, 2017, doi: 10.1016/j.tourman.2016.11.019.

[26] F. Frey, "SPSS (Software)," Int. Encycl. Commun. Res. Methods, no. December, pp. 1-2, 2017, doi: 10.1002/9781118901731.iecrm0237.

[27] E. H. Hernández, P. C. Blanco, A. G. Rodríguez, and J. M. 
Martín, "Design and validation of an observational instrument to assess the technical execution in top-rope climbing," J. Hum. Sport Exerc., vol. 9, no. 1, pp. 111-123, 2014, doi: $10.4100 /$ jhse.2014.91.12.

[28] J. F. Hair, C. M. Ringle, and M. Sarstedt, "PLS-SEM: Indeed a silver bullet," J. Mark. Theory Pract., vol. 19, no. 2, pp. 139-152, 2011, doi: 10.2753/MTP1069-6679190202.

[29] Ilham and Tomoliyus, "Construction of validity and reliability of an observational instrument to assess the technical execution in lead climbing," Int. J. Hum. Mov. Sport. Sci., vol. 9, no. 3, pp. 403-411, 2021, doi: 10.13189/saj.2021.090303.

[30] I. Corresponding, "Partial Least Squares Structural Squation Modeling ( PLS-SEM ) Analysis for Social and Management Research: A Literature Review Agus Purwanto Journal of Industrial Engineering \& Management Research," vol. 2, no. 4, pp. 114-123, 2012.

[31] K. K. K.-K. Wong, “28/05 - Partial Least Squares Structural Equation Modeling (PLS-SEM) Techniques Using SmartPLS," Mark. Bull., vol. 24, no. 1, pp. 1-32, 2013, [Online]. Available: http://marketing-bulletin.massey.ac.nz /v24/mb v24 t1 wong.pdf\%5Cnhttp://www.researchgate. net/profile/Ken Wong10/publication/268449353_Partial Least Squares Structural Equation Modeling (PLS-SEM )_Techniques_Using_SmartPLS/links $/ 54773 \mathrm{~b} 1 \mathrm{~b} 0 \mathrm{cf} 293 \mathrm{e} 2 \mathrm{~d}$ a25e3f3.pdf.
[32] B. S. Joseph, "Athletes' Knowledge about Preventing Sports Injuries Like: Achilles Tendinitis (AT), Runner's Knee (RK)/Patellofemoral Pain Syndrome (PFPS) and Shin Splints (SS), as Prime Prevention Strategies in Slowing Ageing Process," J. Exerc. Sci. Physiother., vol. 12, no. 1, 2016, doi: 10.18376//2016/v12i1/86809.

[33] K.-M. Wang and Y.-C. Huang, "Knowledge and Needs for Prevention and Management of Sports Injury among High/Vocational School Students in Taiwan," Int. J. Sport Heal. Sci., vol. 4, pp. 286-297, 2006, doi: 10.5432/ijshs.4.286.

[34] R. A. Hauser, "Ligament Injury and Healing: A Review of Current Clinical Diagnostics and Therapeutics," Open Rehabil. J., vol. 6, no. 1, pp. 1-20, 2013, doi: $10.2174 / 1874943701306010001$

[35] V. Schöffl, A. Heid, and T. Küpper, "Tendon injuries of the hand," World J. Orthop., vol. 3, no. 6, pp. 62-69, 2012, doi: 10.5312/wjo.v3.i6.62.

[36] T. H. Trojian, "Muscle Contusion (Thigh)," Clin. Sports Med., vol. 32, no. 2, pp. 317-324, 2013, doi: 10.1016/j.csm.2012.12.009.

[37] K. Y. Woollings et al., "Foot overuse diseases in rock climbing: An epidemiologic study," Sport. Technol., vol. 40, no. $1, \quad$ pp. 899-906, 2015, doi: 10.1080/19346182.2015.1107081. 